\section{Patrick Barwise}

is Professor of Management and Marketing at London

Business School.

Seán Meehan

is the Martin Hilti Professor of

Marketing and Change

Management at IMD in

Lausanne.

Keywords: customer responsiveness, customer

satisfaction, customer experience, market orientation, organisational culture
Patrick Barwise

London Business School

Regent's Park

London NW1 4SA, UK

Tel: +44 (0)20 72625050

Fax: +44 (0)20 7724 1145

E-mail: pbarwise@london.edu

\section{Developing a customer-focused mindset}

\author{
Patrick Barwise and Seán Meehan \\ Received (in revised form): 14 July 2005
}

\begin{abstract}
To become customer-focused, companies need clear values based on openness, flexibility and an external focus; an insistence that business cases are supported with current, factual market data; and limited tolerance for trial and error. The aim is to be fast and right in the eyes of customers.
\end{abstract}

\section{From market information to customer responsiveness}

Harold S. Geneen, former chairman of ITT, held that 'It is an immutable law in business that words are words, explanations are explanations, promises are promises, but only performance is reality.' In this paper, we argue that successful companies develop a culture that is appropriately responsive to customers, using what we call 'fast and right' processes, since speed of response is also crucial in competitive markets. It discusses such companies' direct learning from the market, their decision-making process and the role of accountable experimentation. We also summarise the key features of the 'pure air' culture underlying these fast and right processes.

Our starting point is how companies learn about markets. An important element of this is 'immersion' - direct customer contact in the actual buying or usage context - as well as competitor understanding and the use of customer dissatisfaction data to identify generic category benefits with scope for improvement. Of course, firms need formal market research to complement the impressions from direct immersion. But none of this market information achieves anything unless the company learns from it and responds appropriately. It is the underlying values of the organisation which ultimately drive its ability both to sense and to respond to market signals.

\section{How companies learn about markets}

In 1997, while exploring the nature of the relationship between marketoriented values, behaviours and business performance, we conducted a survey of senior managers. Our unit of analysis was UK businesses with responsibility for strategy development and implementation as well as financial performance. The sample frame comprised 1,400 UK-based main operating subsidiaries of a sample of 200 companies quoted on the London Stock Exchange and headquartered in the UK. The survey was endorsed by Lord Marshall (then Sir Colin Marshall, CEO of BA and chairman of the Marketing Council) in the form of an introductory letter. After a pre-mailing announcement, the initial mailing was followed up 
You should still measure customer satisfaction

\section{In themselves the data achieve nothing}

twice; 434 responses were received (a response rate of 31 per cent) from 281 CEOs (61 per cent of responses) and 153 members of the top management team designated by the CEO.

When we investigated senior executive opinion in the UK about customer focus, we were surprised to find that only 234 out of these 434 top managers (54 per cent) agreed with the statement 'We measure customer satisfaction systematically and frequently'. This suggested a less than universal commitment to customer focus. Five years later, the proportion agreeing with the same statement had dropped to 20 per cent. Several factors account for this decline. Response rates to satisfaction surveys have dropped as customers have got fed up with being surveyed. Companies also say that satisfaction scores are a poor predictor of loyalty and tell one nothing about the causes of dissatisfaction, so they are not actionable.

There is some truth in each of these gripes, but you should still measure customer satisfaction to show up short-term and local changes in how well you are meeting customers' expectations, as well as to monitor more general long-term trends. Keep the measure as simple as possible, and be prepared to offer a prize draw or other incentive to get an acceptable response rate, or use a syndicated source such as ACSI. The data - like all data - have their limitations. They must be used in combination with other information and insights. Customer orientation is a commitment to meeting customer needs without overcomplicating things or running around in circles. It is based on a listening culture, but also requires formal data collection from the market. In themselves, however, the data achieve nothing.

\section{Much market research expenditure is wasted}

We estimate that at the end of the 1990s global expenditure on third-party market research had reached $\$ 18 \mathrm{bn}$ annually, a threefold increase during the decade. Around $\$ 2.5 \mathrm{bn}$ of this was directed at measuring customer satisfaction. Unfortunately, we suspect that much of this effort reflects a bureaucratic defence mechanism. Executives are under pressure to have answers about what is going on in their markets. Given the abysmal level of customer satisfaction, we can only assume that much of the huge expenditure on market research is to help clients satisfy and impress their bosses rather than to understand what is going on and react accordingly. This suspicion is supported by academic research in this area: many managers use research results to justify already formed positions. ${ }^{1}$

At a global capital goods organisation we observed, two teams of executives drawn from different product groups were given the same detailed market study and asked to interpret the results and recommend to the corporate centre how the company (not necessarily their business unit) should approach the opportunity. Neither group knew that the other had been asked the same question. Each made a compelling argument that its own product was the perfect solution, and explicitly showed why the other group's product was unsuitable. In isolation, each case was impressive, persuasive and apparently customer-focused. But taken together with the other group's case, each had clearly used the data to support its own 


\section{'Customer sensing' is commonplace}

\section{Deep down, managers were unwilling to respond to the needs and demands of customers}

position. As the saying goes, they used the data as a drunk uses a lamppost, for support not illumination. This is fairly typical.

\section{How companies actually learn about what customers value}

Curious as to what was really going on, we asked senior UK executives about how their firms learn about customers and competitors, how much different functions interact to create customer value and how they describe their businesses' underlying value systems.

Not surprisingly, we found a strong claimed belief in the value of achieving a good understanding of customer needs. 'Customer sensing' is commonplace. The most significant statistically observed difference in the approaches to understanding customers between the high- and lowperforming companies is that in the most successful ones, managers of all departments - finance, administration, operations, R\&D and human resources as well as sales and marketing - are in regular contact with customers, getting a better, more realistic, understanding of the customer's experience. There is also an important difference in how those meetings take place: in short, business meetings with customers focusing on current issues are most effective while social interactions do not help so much.

We also found formal 'competitor sensing' to be much less widespread. It tends to be undertaken disproportionately by high-performing companies. Perhaps it is this combination that enabled 74 per cent of respondents in the high-performing companies (compared to only 44 per cent of respondents in the low-performing companies) to claim 'All our managers understand how everyone in our business can contribute to creating customer value'. Again, the focus is on the CEO's perception that all managers have this insight. These findings suggest that high performers are not slaves to the questionnaire or the formal process, but understand and act on the essence of Drucker's assertion so many years ago:

'Marketing is so basic... it encompasses the entire business. It is the whole business seen from the point of view of its final result, that is, from the customer's point of view. Concern and responsibility for marketing therefore must permeate all areas of the enterprise.'

The study convinced us that, although companies were widely engaging in customer-sensing activities, especially formal market research, these were often ineffectual because, deep down, managers were unwilling to respond to the needs and demands of customers. This led to our model of customer orientation and how in practice it works to enhance business performance (Figure 1).

\section{Values drive both market sensing and customer responsiveness}

Our data suggested that, while market sensing can be valuable, it was not the primary driver of customer orientation. Its effect on performance was indirect. Equally if not more critical was the degree to which the organisation was responsive to what it learned about the market. The driver of both the nature (but not the extent) of market sensing and the 


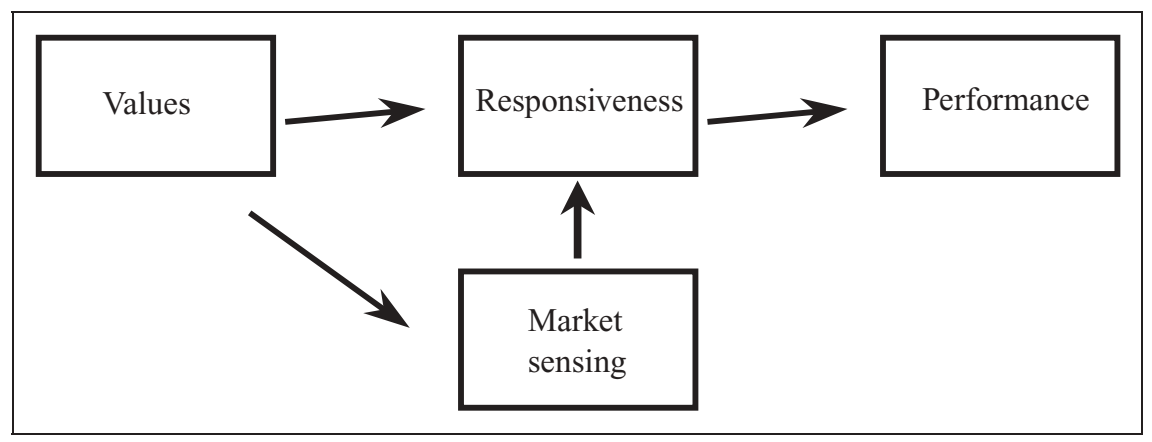

Figure 1: How customer orientation really works

\section{Openness, flexibility and an external focus}

degree of responsiveness was the organisation's value system - what really mattered, its culture.

Getting an objective measure of a complex construct such as organisational culture or values, including where the customer fits in, is difficult. Asking managers whether customers are important is, in any form, folly. Rather than crudely asking respondents to describe their culture in terms of the role or priority of the customer, assessing it indirectly through the 'competing values' ${ }^{3}$ approach can tell us more about actual customer focus. Our research suggests that companies which value openness and flexibility and are more concerned with external rather than internal matters are more likely to be customer-responsive and enjoy superior performance.

George Day of the Wharton School suggests that General Electric and Citibank are good examples of such so-called 'adhocracies'. ${ }^{4}$ He points out that they value 'flexibility and adaptability while maintaining a focus on the external environment'. The dominant values of an adhocracy are entrepreneurship, creativity, adaptability, autonomy and willingness to experiment. They value growth/acquisition of new resources, innovativeness and competitiveness, combined with a healthy dose of respect for people. They are diametrically opposite to the bureaucratic archetype, the hierarchy.

Hierarchies tend to be inward-looking and rigid, prioritising order and routine. Although one might expect them to perform well in mature industries and stable markets, our data suggest that, irrespective of the industry (high tech/low tech, products/services, B2B/B2C), the more bureaucratic an organisation is, the less likely it is to be commercially successful. But a firm with no bureaucracy at all would suffer from insufficient direction and control. Adhocracy needs to be deliberate, and the behaviour it tolerates needs to be aligned to firm-wide objectives. Perhaps surprisingly, hierarchy can play an important role.

\section{Case study: Toyota - Focusing on the basics in the luxury market}

Toyota entered the US market in 1957, a time of big gas-guzzlers, well before the first oil crisis. Initial impressions of Toyotas were of quirky, small, low-quality Asian cars. These perceptions slowly evaporated as 


\section{Lexus meant dealing with the basics to perfection}

\author{
Rethinking what \\ 'luxury' meant in \\ practice
}

motorists reported satisfaction with the cars' excellent reliability and value for money. Eventually, with US-based state-of-the-art manufacturing facilities, Toyota built its position as the world's most efficient manufacturer of quality cars for the masses. The Toyota advantage was shown vividly by McKinsey consultants who compared sales price, incentives and residual values of the Toyota Corolla and the Chevrolet Prizm - identical cars except for the badge, designed by Toyota and manufactured on the same assembly line. ${ }^{5}$ Although GM spent $\$ 750$ per car more than Toyota in buyer incentives, the Toyota outsold the Chevrolet by a factor of four and held its value longer. Perceived quality had real market value.

The late 1980s represented an important departure when Toyota developed the Lexus, its first venture into the luxury end of the market. Could it leverage mass-market quality in the luxury market? What would 'quality' mean? In the case of Lexus, it meant dealing with the basics to perfection. The key to understanding the otherwise well-known Lexus success story lies in Toyota's customer-focused mindset.

\section{Toyota luxury pursues the essentials}

During the early 1980s, affluent US baby-boomers favoured foreign luxury car brands like Mercedes and BMW over domestic brands like Cadillac. Toyota saw European brands as weak on issues such as price and the cost of maintenance. Its research showed that the primary motivation for Mercedes buyers in the USA was 'prestige image' based on the brand's long-established European and engineering heritage. Toyota believed that there would be a market, even among many Mercedes buyers, for a better-value luxury car. The design brief suggested that Toyota realised that 'basic performance as a vehicle' could be a primary motivation for buyers - even at the high end of the market:

'A luxury sedan with a sense of intelligence which excludes gimmicks and pursues the essentials... A car with a respect for human beings, which moves not automatically, not wastefully, but faithfully by the driver's intention... We are going to produce the ultimate luxury car based upon our 50 years of experience in manufacturing an automobile. ${ }^{6}$

In addition to redefining luxury, Toyota would also need to find new or better ways of communicating prestige. A Toyota report stated:

'We cannot sincerely communicate such a prestige image without having all the "facts" to satisfy customers; not only having the best product, but also in creating the best showrooms, with the most sophisticated sales manners and the best after-sales service - all being customer oriented.'

Toyota's design and engineering team had to rethink what 'luxury' meant in practice. For example, they had observed that the running cost of many luxury cars increases with age. So they would have to find ways to eliminate the main causes of depreciation and long-term maintenance costs such as rust and deteriorating paintwork. In pursuit of this aim, 
Toyota bought several competitor vehicles and evaluated them for deterioration on 96 different dimensions of technical performance. Flaking chrome plating and uneven fading of interior colour, considered normal by competitors, were simply unacceptable to Toyota. Its design team increased the thickness of the chrome plating by a factor of eight; adopted heat- and sunlight-reflecting window glass; and painted the body with six coats. When the car was left in the desert for a year along with competitor cars, it suffered no weathering and emerged in much better condition than the rest.

The new Lexus dealership would comprise 80 dealers selected from 1,500 who had initially expressed interest. Many owned Mercedes and BMW dealerships. Only those with the highest customer satisfaction index (CSI) scores were seriously considered. Applicants had to submit business plans. They also had to:

- provide documentation of delivering both high CSI and sales leadership within their primary market area

- produce a record of profitable dealer operations

- demonstrate an understanding of the high level of personalised service expected by luxury car buyers

- commit to the capital $(\$ 3 \mathrm{~m}-5 \mathrm{~m})$ and staffing investments to ensure a consistent customer experience.

Toyota's commitment to make owning a Lexus an exceptional experience by extreme attention to the basics was tested less than three months after launch. Lexus received one customer complaint regarding a cruise control malfunction and several complaints about one of the stop lights. Its response was to recall all 8,000 cars sold in the first quarter. This was done prior to receiving any regulatory guidance. Dealers contacted all owners personally and made the repairs quickly. The cars were returned washed and with a free full tank of petrol. Takao Kawamura, head of US after-sales, led the recall decision. He commented:

\section{Lexus is a 'culture' developed from Customer First}

'Lexus wanted to proceed in a manner that was beyond customers' expectations. We believed that the bottom line of prestige image was a feeling of trustworthiness. . Lexus is not a mere name of a model or a franchise. . . it is a "culture" developed from Customer First.'

Lexus launched in the USA with the LS 400 in January 1989. A year later it was voted number one in all categories, including customer satisfaction, in Car \& Driver's new buyers' study. It had also become the number one luxury import, selling over 70,000 cars - more than either Mercedes Benz or BMW. In 1991 Lexus ranked overall number one in J. D. Power's customer satisfaction survey.

\section{Toyota's compass: The Toyota Way}

'The Toyota Way' defines Toyota's expectations and guides its behaviour. It is as close as anyone can come to describing its culture - and it guided the Lexus launch in the USA. In 2001 Toyota codified The Toyota Way (Figure 2). It was seen by Fujio Cho, Toyota's president, as an important 


\section{Continuous improvement and respect for people}

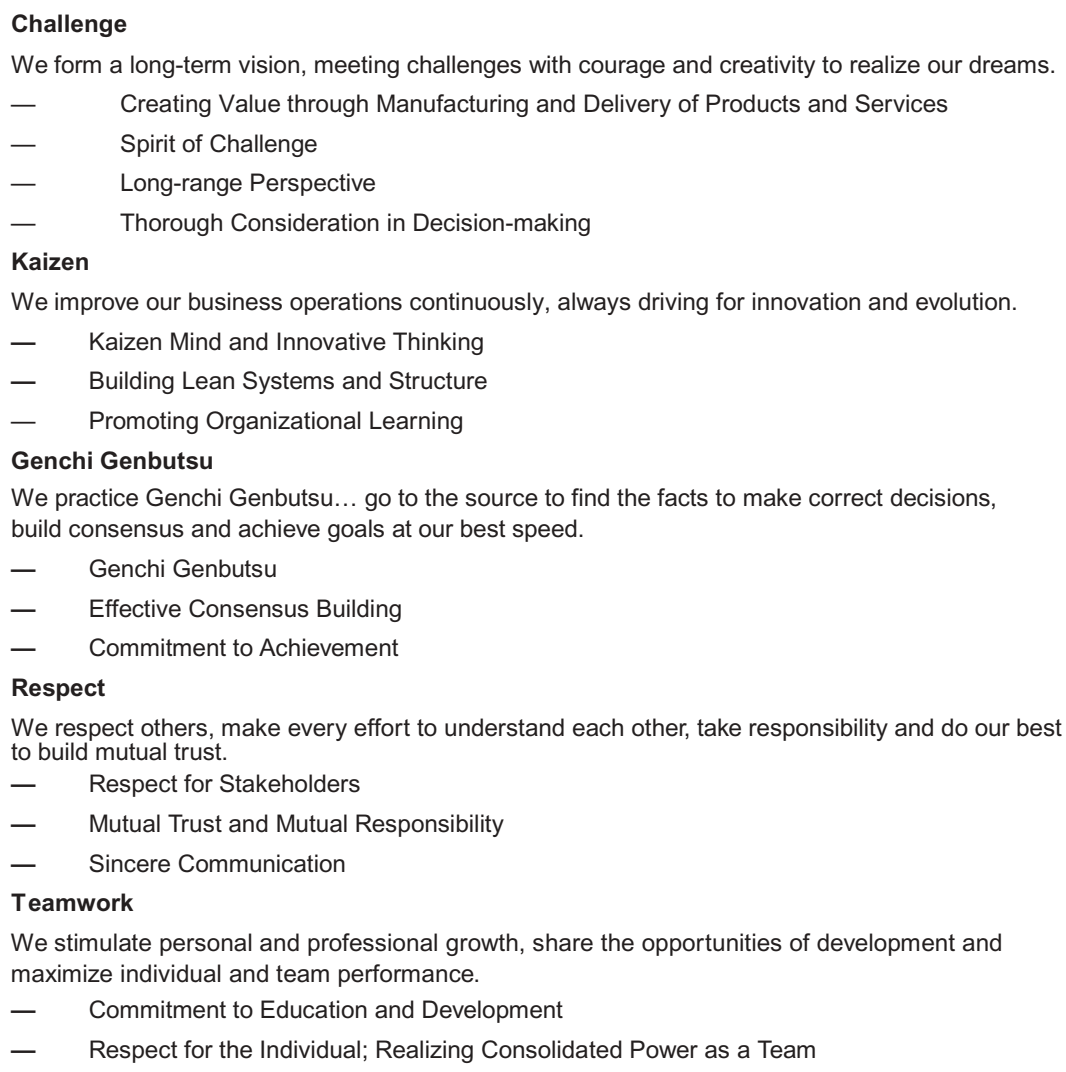

We respect others, make every effort to understand each other, take responsibility and do our best to build mutual trust.

- $\quad$ Respect for Stakeholders

- Mutual Trust and Mutual Responsibility

- Sincere Communication

Teamwork

We stimulate personal and professional growth, share the opportunities of development and maximize individual and team performance.

- Commitment to Education and Development

- $\quad$ Respect for the Individual; Realizing Consolidated Power as a Team

Figure 2: The Toyota Way 2001

Source: Internal Toyota documents

tool for enabling new members of the fast-growing global Toyota family to understand 'the unique and outstanding elements of our company's culture and success'. Implicit throughout is that all activities enable Toyota to make great cars and provide great service — that's it.

'The Toyota Way 2001' encompasses five concepts that support two main pillars: Continuous Improvement (encompassing Challenge, Kaizen and Genchi Genbutsu) and Respect for People (encompassing Respect and Teamwork). In the preface to 'The Toyota Way', Fujio Cho set out his expectations:

'We are never satisfied with where we are and always improve our business by putting forth our best ideas and efforts. We respect people, and believe the success of our business is created by individual efforts and good teamwork. All Toyota team members, at every level, are expected to use these two values in their daily work and interactions.'

This relentless focus on pushing, moving forward, doing better appears to work. Toyota has enjoyed spectacular success in the USA and is well positioned to capitalise on the increasing liberalisation of the EU market. Its market capitalisation of \$134bn in June 2005 dwarfed those of DaimlerChrysler (\$45bn), Ford (\$20bn) and General Motors (\$17bn). ${ }^{8}$ 


\section{'Simply better' organisation-wide}

\section{Focus precisely on what delivers customer value}

The Toyota success story is not one of product engineering genius, although the makers of the world's best-selling gasoline-electric hybrid car, the Toyota Prius, and many other product firsts may disagree. Nor, historically, has it been one of style, no matter how proud the executives at Toyota Europe are of the Yaris, winner of the coveted European Car of the Year in 2000. Nor is it about emotion, although Toyota's entry into Formula 1 motor racing in 2002 is starting to bring more emotion to the brand. Toyota has, however, from a platform of quality performance built in at the factory, been consistently recognised by J. D. Power as the auto industry's number one. ${ }^{9}$ Although the brand leaves some 'petrol-heads' cool, over 4 million car buyers a year around the globe disagree. The basics matter, and on these Toyota adopts a customer-first perspective and wins - even in the luxury market.

Toyota's customer focus and relentless innovation reflect a successful 'simply better' organisation culture. This mindset underlies all the specific execution best practices in customer-focused companies.

\section{Hierarchy can improve performance: Swiss Re North America}

A clear sense of hierarchy can deliver efficiency and effectiveness and actually reduce unhelpful bureaucracy, according to Jacques Dubois, chairman of Swiss Re North America. ${ }^{10}$ Cost consciousness is an obsession for Dubois, who tells his executives that 'service is the refuge of the inefficient'. This does not reflect an anti-customer approach quite the contrary. Dubois demands that his executives focus on precisely what delivers customer value. His point is that the service offered should be in line both with the firm's strategy and with customers' interest and willingness to pay. Too often it is neither. Dubois attributes his cost consciousness to the stringent terms imposed by the backers of the leveraged buyout of the General Reinsurance Company he led in 1988. Small negative variances would have derailed the entire deal. His approach was to keep everything focused and simple.

Dubois argues that it is critical for the top of the organisation to be intimately familiar with what is really going on in the market. He observes that managers often see their job as delegating, which he believes is dysfunctional, since it puts decisions in the hands of potentially inadequately qualified people. Dubois goes further: 'By raising decision making to the highest level possible, we get to see our people in action. It motivates them. They deal with the top.' There are no standing committees, but meetings happen as needed. Decisions get made.

\section{How Cemex uses information systems}

Carlos Zambrano, CEO of giant cement producer Cemex, uses information systems to cultivate an entrepreneurial and energetic organisation. ${ }^{11}$ His systems place him in direct contact with all elements of the massive organisation. He can monitor plant productivity globally and in real time. If he detects that one plant's operating levels are below the benchmark for the other 49 plants, he can call a worker directly to find 


\section{Managing a duality - flexibility and efficiency}

\section{If everyone is comfortable, they are not learning anything}

out why. If he wants to check out how sales worldwide were in the last 24 hours, he can. That capability has changed how Cemex people manage their time and work. They no longer have to stop what they are doing to look for information. The data are readily available.

\section{Responsiveness and adaptability}

Critically, as with Swiss Re North America and Cemex, both of which find virtue in sensible hierarchy to enhance customer responsiveness, the high-performing companies we observed tended to be flexible and claimed to have the ability to respond and adapt to changing market conditions. Their employees also felt that they were treated well and were a part of the 'deal'. Respondents suggested that, in terms of those values that provided a shared sense of purpose in their companies (sometimes referred to as 'organisational glue'), these high-performing companies valued loyalty and tradition as well as innovation, and development over mindless micro-management characterised by an overemphasis on goals, tasks, rules and policies. Creating a flexible organisation that is responsive, focused and efficient thus involved managing a duality.

\section{How companies manage the duality}

We attribute companies' ability to manage the duality — flexibility plus order and efficiency - to their transparency and inclusiveness. One CEO told us that the two most critical drivers of employee morale were understanding the firm's strategy and having faith in the ability of your immediate boss to contribute effectively to making the strategy a success. This combination is more than just pleasant. It has a decisive impact on how information is treated and, therefore, the rate at which the organisation learns about and responds to events in the market. In highperforming companies, trust is high and market insights are relatively depoliticised.

So, being customer-focused is not about corporate rhetoric, nor is it even just about market sensing. It is the ability to create continuous learning about the market and respond appropriately to what is being learned. This responsiveness appears to be dependent on, or at least interdependent with, the underlying organisational culture. Creating a culture that is appropriately responsive is thus imperative for those seeking to be 'simply better'.

\section{Creating a culture that is appropriately responsive to customers}

According to Don Lehmann of Columbia University, 'The term "learning organization" implies being exposed to things you're not comfortable with. If everyone is comfortable, they're not learning anything.'

Customer responsiveness is intuitively appealing: develop your organisation's ability to understand what customers want and need, know what else is or could be on offer and let nothing stop you providing the right solution. This is clearly simplistic, however: organisational rigidities exist for a reason, usually to do with achieving operating efficiencies and economies of scale that allow you to operate at a cost level that is 
Fast and right

\section{Direct learning plus market research}

attractive to most customers and competitively sustainable. We hope it is clear we are not suggesting that being responsive to customers means that you always give them whatever they want - being what George Day calls 'customer-compelled', like IBM in the early $1990 \mathrm{s.}^{12}$ So what is customer responsiveness and why does it matter?

\section{What customer responsiveness is and why it matters}

Customer responsiveness means being fast and right in the eyes of customers. ${ }^{13}$ To explore this view, together with Charlie Dawson of The Foundation (a London-based consultancy specialising in this area) we interviewed ten high-profile UK CEOs with marketing backgrounds. ${ }^{14}$ They saw customer responsiveness as '.. accurately and insightfully giving customers what they need, want or don't yet know they want. And... consistently doing so more quickly than anyone else and rapidly enough to retain the value of the decision or idea for customers.'

The value of being right about customer needs is obvious. But the value to both the customer and the business also depends on the speed of the response. Satisfying customers is usually not that hard; it simply takes time and money to get things right. Enough testing and piloting and most companies will get there in the end. Being fast is not that hard either. But being both fast and right presents a challenge.

'Fast and right' is not a risk-taking, 'failure is good' culture. Interviewees conveyed both intolerance of doing the wrong thing and impatience about responding too slowly. Practically speaking, to enhance customer responsiveness companies should embrace three key sets of behaviours that lead to decisions being both faster and better. We call these direct learning (comprised of immersion, intuition and fact-based market research), hard work decision making and accountable experimentation. These behaviours are supported by what we call a 'pure air' culture (Figure 3).

\section{Impatience and intolerance are good}

The particular form of learning, decision making and resource allocation represented in Figure 3 is based on the politically incorrect notion that impatience and intolerance are good.

Direct learning increases a team's ability to make the right decisions using judgments based on immersion, intuition and fact-based market research. Many executives interviewed characterised the intuition of managers who were immersed in real market experiences as a crucial competitive tool. Intuition is especially important in the 'creative' industries such as television, fashion and music, where every episode, design or song is a new product and formal market research is a poor predictor of market response and can discourage risk taking. Eric Nicoli, chairman of music group EMI, pointed out that the reinvention of a pop singer like Robbie Williams or the discovery of bands like Coldplay and Radiohead happened because individuals had instinctively sensed these opportunities and fought hard for them. To the executives interviewed, fact-based market research then provides a basis for checking the validity of at least some opinions about market opportunities, backed up by the 


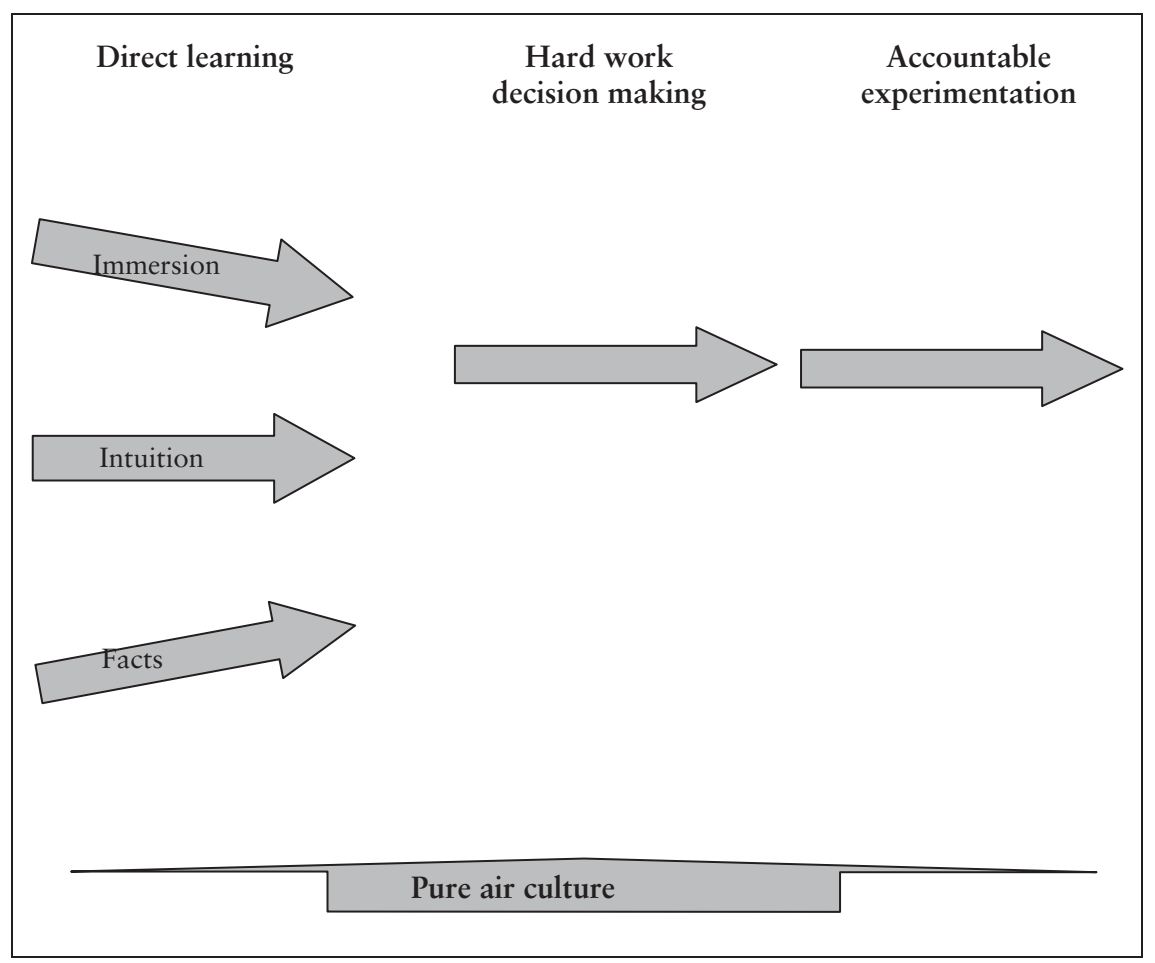

Figure 3: 'Fast and right' processes and a 'pure air' culture

judgment derived from immersion and intuition. Also, some market research, such as pre-testing advertisements, can help improve execution.

\section{Fast and right in Silicon Valley}

Hard work decision making is about replacing frantic activity with rigorous debate within a better-informed team, using high standards to avoid wasting effort. One place where hard work decision making is essential for success is Silicon Valley. Stanford professor Kathleen Eisenhardt and her co-researchers compared the behaviour of top management teams in highly successful and less successful Silicon Valley firms. ${ }^{15}$ The key difference was in the quality of their debates.

The best management teams managed to express their disagreements frankly without generating interpersonal conflict. They did this by focusing on current factual data, building multiple alternatives, creating common goals (such as beating the competition), developing a balanced power structure within the group and using humour to release interpersonal tensions. In contrast, the less successful teams relied on opinions, wishes and guesses, focused on only one or two alternatives, ignored common goals, let autocrats or - at the other extreme - laissezfaire rule and had less fun.

Another difference was in the behaviour of the leader. Willingness and

\section{Listening is not weakness} ability to listen are essential attributes of all good managers, but listening is not the same as weakness. On the contrary, in the successful management teams, if discussion of an issue did not lead to consensus, the leader made the final decision, guided by input from the rest of the 
In a startup or turnaround situation, 'fast' matters more than 'right' group. Crucially, even those who have argued for a different course of action usually throw themselves wholeheartedly into executing the decision once it is made - if they believe their views were genuinely listened to. This approach, which Eisenhardt called 'consensus with qualification', limits conflict and leads to 'fast and right' decisions, at least in comparison to decision making by fiat or deadline, or endless debate in a fruitless search for consensus.

\section{Early turnaround versus long-term success}

Ideally, a successful organisation would have many empowered individuals all capable of making fast and right decisions. It is hard to get to that stage. The key seems to be clear, top-down guidance of thought and action (but not detailed prescription) as the dominant way of working. The mitigating factor is that this is based on up-to-date objective facts and on what is right for the customer. Depending on the stage that the company is at (startup or early turnaround versus long-term success), this top-down approach works in different ways.

In a startup or turnaround situation, when 'fast' often matters more than 'right', an experienced, small and coherent team can provide effective direction. But the decision-making group has to be expanded if success is to be sustainable over the long term. This happens as others in the organisation interact with the top team. Rather than acting as a bottleneck, such interaction serves to educate this wider group about the degree of market intimacy that must underpin all key initiatives. Intolerance for ideas which are not firmly rooted in the reality of the marketplace is seen as a positive force for change, 'purifying' the organisation's thought process.

Thorough 'purification' takes time, but eventually ensures that everyone involved in debating issues and making decisions has a shared basis for interpreting market dynamics. Until this shared view is in place, the big decisions have to be contained within the small top team. Over time, by being involved in these debates and decisions, more and more people around the business understand the high standards and the unyielding process. Those who are going to be able to live with it, and thrive on its exacting consequences, will stay and enjoy more autonomy as a reward for 'getting' the approach.

Tesco illustrates what the process is like once a business is well established on a successful path. At Tesco, a clear and well-understood vision for the business made it possible to push responsibility a long way down: buyers had just one six-monthly meeting where they set out their plans to hit their numbers. They had the ability to dictate launches, promotions and pricing. The onus was on the individual buyer to make it work: there was clear overall direction and lots of freedom for initiative, but if something did not work it was clear who was responsible. This approach was popular with suppliers (packaged goods manufacturers) as well as being customer-focused: suppliers found Tesco tough on price but less bureaucratic and more responsive than its competitors.

Accountable experimentation requires a combination of widespread good-quality learning and high hurdles for decision making to ensure 


\section{Aim for 'seven out of ten' successful experiments}

\section{A 'pure air' culture is not comfortable or cosy}

that, when trials do happen, they are already building on considerable data, thought and discussion. This has the benefit that a smaller group of well-informed bright people can operate better and faster than a disparate group running multiple uncoordinated trials. Also, by having fewer experiments, each gets more attention and is carefully set up and planned. ${ }^{16}$

Mistakes are still expected. Indeed, the view was expressed in our research that if there were no mistakes then the organisation had not been trying hard enough. In our research some interviewees talked about 'seven out of ten' as the kind of hit rate they were looking for - high and exacting but not risk-free. This tolerance of 30 per cent failure was also expressed as an acceptance, enthusiasm even, for U-turns and valuing someone's ability to spot an unsuccessful experiment while they were working on it and close it down.

\section{'Pure air' culture}

Underlying direct learning, hard work decision making and accountable experimentation in the successful organisations we studied was a 'pure air' culture. The 'pure air' culture was not comfortable or cosy. Rigour and unyielding standards appeared to be important elements of the way these companies operated.

The first feature of a pure air culture is the way that challenge and debate are seen as forces for good, not just in the top management team but throughout the organisation. Because the process of discussing conflicting ideas and views is based on facts and objective observation, it encourages people to share learning and build judgment.

The second feature is that no one expects an easy 'yes' to their proposals. By requiring people to make a strong case if they are to be given the go ahead, the organisation toughens up but also fully values opportunities when they do arise. Peter Burt, chairman of Bank of Scotland, spoke enthusiastically about an executive who had championed a problematic mortgage plan for elderly homeowners. He had been rebuffed several times but did not give up.

The consequence of all of this is the purging of poor argument and lack of rigour. While a balance must always be struck between fast and right, compromise is avoided where possible. There are not fewer ideas being discussed and progressed, just fewer bad ones. Like purer air, this is a clearer environment within which strong people and strong thinking can thrive.

David Robey, Tesco's former director of corporate marketing, described the company in the mid-1980s and early 1990s as being like the Wild West. It was aggressive, highly disciplined and very 'can do', but fair with no hidden agendas. People were allowed to challenge and take chances. If they succeeded, even if they were difficult characters, they were highly valued. Conversely, fail too often and you were out.

Creating such a fast and right approach to customer responsiveness is difficult. It requires clear leadership and signalling. For a start, the top management needs to show its commitment through direct learning. At Berkeley Homes, after a week's immersion on a building site, chairman Tony Pidgley appeared to be moving towards a fast and right approach. 
He certainly wanted customer-focused action. A week on site represented one part of direct learning and, critically, it resulted in his moving the company towards a 'pure air' culture. Think of the impact on his management team when, at their meeting, he produced the irrefutable physical evidence that the system to deliver materials on site was failing. When one manager asserted that, despite Pidgley's evident disappointment, they had 'the will' to do right by the customer, Pidgley exploded: 'We haven't got a will here. . I'm not having it today that we've got a will. We talk about it, I write memos. . . none of it is in place. . . it's lip service.' Pidgley appeared totally re-energised from his week on the building site. His direct learning had made him the authority on customer service.

Just as thinking 'outside the box' was the expected approach for managers in the 1990s, we expect a return to fundamentals to become today's big idea. 'Back to basics' is already gaining ground as the new staple of the executive suite. We can expect headlines like 'GE chairman goes back to basics ${ }^{17}$ to become widespread. We do caution, however, that a successful return to basics is not about slashing and burning parts of your business; rather, it is about being 'simply better'. This requires far more than doing more market research. It is a commitment from the top to transform the entire culture of the business - starting at the top itself.

\section{Clear values and beliefs}

\author{
Current, factual data
}

\section{Limited experimentation}

\section{Idea check: Are you serious about customer responsiveness?}

- Does your organisation have clear values and beliefs? Written or not, yes it does. The question is, is everyone's interpretation consistent? If you believe in customer focus, help everyone understand what this really means - what behaviours should be expected under which circumstances.

- Are business cases well supported with current, factual market data? Market research reports are often abused. Ensure that case promoters have a good understanding based on both first-hand experience and hard data.

- Do you tolerate a lot of trial and error? Do not. Limit the resources available for such trial and attach some sort of cost to them. Free trial leads to sloppy thinking.

\section{Acknowledgments}

This paper is based on Chapter 6 of Patrick Barwise and Seán Meehan's recent book, Simply Better: Winning and Keeping Customers by Delivering What Matters Most, ${ }^{18}$ and draws extensively on the major research programme carried out for the book, winner of the American Marketing Association's 2005 Berry AMA Prize for the best recent book in marketing.

\section{References}

1. Moorman, C., Zaltman, G. and Deshpande, R. (1992) 'Relationships between providers and users of market research: The dynamics of trust within and between organizations', Journal of Marketing Research, Vol. 29, August, pp. 314-329. 
2. Drucker, Peter F. (1955) The Practice of Management, Butterworth-Heinemann, Oxford.

3. For the competing values framework, see Quinn, R. E. and Rohrbaugh, J. (1983) 'A spatial model of effectiveness criteria: Towards a competing values approach to organizational analysis', Management Science, Vol. 29, pp. 363-377; Quinn, R. E. (1988) Beyond Rational Management, Jossey Bass, San Francisco. This operationalisation of culture as values has been adopted in the market orientation literature — see Deshpande, R., Farley, J. and Webster, F. Jr (1993) 'Corporate culture, customer orientation and innovativeness in Japanese firms: A quadrad analysis', Journal of Marketing, Vol. 57, January, pp. 23-37; Moorman, C. (1995) 'Organizational market information processes: Cultural antecedents and new product outcomes', Journal of Marketing Research, Vol. 32, pp. 318-335.

4. Day, George (1999) The Market Driven-Organization: Understanding, Attracting, and Keeping Valuable Customers, Free Press, New York, pp. 54-55.

5. Chatterjee, Anjan, Jauchius, Matthew, E., Kass, Hans-Warner and Satpathy, Aurobin (2002) 'Revving up auto branding', McKinsey Quarterly, No. 1, p. 134.

6. Internal Toyota documents.

7. Ibid.

8. Financial Times (2005) 'FT Global 500', Financial Times, 11 June, pp. 07-14.

9. Since 1990, Toyota and Lexus have received 136 J. D. Power quality awards for various automobile models and manufacturing plants. Globally, Toyota has received 12 J. D. Power awards for initial quality. Lexus alone has received 70 top rankings for quality and customer satisfaction. This information was gathered through e-mail correspondence with J. D. Power and Associates on 6 August 2002.

10. Jacques Dubois, interview with author, June 2001.

11. Marchand, Donald, Chung, Rebecca and Paddack, Katarina (2003) Global Growth Through Superior Information Capabilities, Case GM 953, IMD, Lausanne.

12. Day, ref. 4 above, pp. 28-31.

13. Meehan, Seán and Dawson, Charlie (2002) 'Customer responsiveness: Getting it fast and right through impatience and intolerance', Business Strategy Review, Vol. 13, No. 4, p. 26.

14. These included Sir Peter Davis (CEO, Sainsbury's), Luc Vandevelde (chairman, Marks \& Spencer), Peter Burt (CEO, Bank of Scotland) and Eric Nicoli (chairman, EMI).

15. Eisenhardt, Kathleen M., Kahwajy, Jean L. and Bourgeois, L. J. III (1997) 'Taming interpersonal conflict in strategic choice: How top management teams argue, but still get along', in Papadakis, Vassilis and Barwise, Patrick (eds) Strategic Decisions, Kluwer, Norwell, MA, pp. 65-83.

16. This produces a similar benefit to BP's system in which peers from different business units meet in non-hierarchical groups to discuss and debate and take advice on their strategies. Further, they allocate fixed and scarce resources among themselves. They operate their own internal capital market and all, through additional peer-group-wide stretch goals, share a vested interest in the return on individual investments. See 'Restructuring internally for strategic customer focus', The Corporate Executive Board, January 2003. 'Project Support Desk Brief', pp. 4-7.

17. Wall Street Journal Europe (2003) 'GE chairman goes back to basics', Wall Street Journal Europe, 2 June.

18. Barwise, Patrick and Meehan, Seán (2004) Simply Better: Winning and Keeping Customers by Delivering What Matters Most, Harvard Business School Press, Boston, MA, available at www.simply-better.biz. 